\title{
An Efficiency of Resource Allocation Research Based on DEA Within 30 Ethnic Minority Autonomous Prefectures
}

\author{
Jianzhong Zhang ${ }^{1}$ and Qiusheng $\mathrm{Lu}^{2, *}$ \\ ${ }^{1}$ Economic and Management Department, Hubei University for Nationalities, Enshi, China \\ ${ }^{2}$ Economic and Management Department Hubei University for Nationalities, Enshi, China \\ *Corresponding author:qiusheng1413@163.com
}

\begin{abstract}
The 12th Five-Year is an important strategic opportunity period for the economic and social development in ethnic minority regions of China. The development strategy of ethnic minority areas should adhere to Scientific Outlook on Development as a guide, suit the measure to local condition, constantly optimize and improve the efficiency of resource allocation then further achieve economic and social scientific development with the national policy support for ethnic minorities. In this paper, the evaluation index system of input and output efficiency of resource allocation in Minority Autonomous Prefecture is established, and the DEA model is the main analysis tool for comparing China's resources allocation efficiency in 30 Ethnic Minority Autonomous Prefectures, and proposes some policy recommendations on optimization of resources allocation.

Keywords. DEA Model; Ethnic Minority Autonomous Prefecture; Resource Allocation.
\end{abstract}

\section{Introduction}

China is a multi-national country composed of 56 ethnic groups. To guarantee the construction and promotion of economic and social development in Ethnic Minority Areas, the Party and the Government design national regional autonomy system according to "Big Mixing-up, Small Inhabit" nation distribution characteristic and the historical evolution of Chinese nation. Among them, the ethnic minority autonomous prefecture is situated between the autonomy region and autonomy county level and unit, but also is a part of our local government. At present, there are 30 ethnic autonomous prefectures in Yunnan, Xinjiang and other nine provinces (see table 1).

Table 1. The Basic Situation of China's Ethnic Autonomous Prefecture.

\begin{tabular}{|l|l|l|l|l|}
\hline $\begin{array}{l}\text { Serial } \\
\text { Number }\end{array}$ & Autonomous Prefecture & Affiliation & $\begin{array}{l}\text { Establishment } \\
\text { Time }\end{array}$ & State Capital \\
\hline DMU $_{1}$ & $\begin{array}{l}\text { Korean Autonomous Prefecture of } \\
\text { Yanbian }\end{array}$ & Jilin Province & $1952-9-3$ & Yanji City \\
\hline DMU $_{2}$ & Tibetan Autonomous Prefecture of Ganan & Gansu Province & $1953-10-1$ & Hezuo City \\
\hline DMU $_{3}$ & Hui Autonomous Prefecture of Linxia & Gansu Province & $1956-11-19$ & Linxia City \\
\hline DMU $_{4}$ & Tibetan Autonomous Prefecture of Yushu & Qinghai Province & $1951-12-25$ & Jiegu Town \\
\hline DMU $_{5}$ & $\begin{array}{l}\text { Tibetan Autonomous Prefecture of } \\
\text { Hainan }\end{array}$ & Qinghai Province & $1953-12-6$ & Qiabuqia Town \\
\hline DMU $_{6}$ & $\begin{array}{l}\text { Tibetan Autonomous Prefecture of } \\
\text { Huangnan }\end{array}$ & Qinghai Province & $1953-12-22$ & Longwu Town \\
\hline DMU $_{7}$ & Tibetan Autonomous Prefecture of Haibei & Qinghai Province & $1953-12-31$ & Xihai Town \\
\hline DMU $_{8}$ & Tibetan Autonomous Prefecture of Golog & Qinghai Province & $1954-1-1$ & Dawu Town \\
\hline DMU $_{9}$ & $\begin{array}{l}\text { Haixi Mongolian Tibetan Autonomous } \\
\text { Prefecture }\end{array}$ & Qinghai Province & $1954-1-25$ & Delingha City \\
\hline DMU $_{10}$ & $\begin{array}{l}\text { Bayinguoleng Mongolian Autonomous } \\
\text { Prefecture }\end{array}$ & Xinjiang Province & $1954-6-23$ & Korla City \\
\hline
\end{tabular}




\begin{tabular}{|c|c|c|c|c|}
\hline $\mathrm{DMU}_{11}$ & $\begin{array}{l}\text { Mongolian Autonomous Prefecture of } \\
\text { Bortala }\end{array}$ & Xinjiang Province & $1954-7-13$ & Bole City \\
\hline $\mathrm{DMU}_{12}$ & $\begin{array}{l}\text { Kirgiz Nationality Autonomous } \\
\text { Prefecture }\end{array}$ & Xinjiang Province & $1954-7-14$ & Artux City \\
\hline $\mathrm{DMU}_{13}$ & Hui Autonomous Prefecture of Changji & Xinjiang Province & $1954-7-15$ & Changji City \\
\hline $\mathrm{DMU}_{14}$ & Yili Kazak Autonomous Prefecture & Xinjiang Province & $1954-11-27$ & Yining City \\
\hline $\mathrm{DMU}_{15}$ & $\begin{array}{l}\text { Xiangxi Tujia and Miao Autonomous } \\
\text { Prefecture }\end{array}$ & Hunan Province & $1952-9-3$ & Jishou City \\
\hline $\mathrm{DMU}_{16}$ & $\begin{array}{l}\text { Enshi Tujia and Miao Autonomous } \\
\text { Prefecture }\end{array}$ & Hubei Province & $1983-12-1$ & Enshi City \\
\hline $\mathrm{DMU}_{17}$ & $\begin{array}{l}\text { Qiandongnan Miao and Dong } \\
\text { Autonomous Prefecture }\end{array}$ & Guizhou Province & $1956-7-23$ & Kaili City \\
\hline $\mathrm{DMU}_{18}$ & $\begin{array}{l}\text { Qianxinan Buyei and Miao Autonomous } \\
\text { Prefecture }\end{array}$ & Guizhou Province & $1982-5-1$ & Xingyi City \\
\hline $\mathrm{DMU}_{19}$ & $\begin{array}{l}\text { Qiannan Buyei and Miao Autonomous } \\
\text { Prefecture }\end{array}$ & Guizhou Province & $1956-8-8$ & Douyun City \\
\hline $\mathrm{DMU}_{20}$ & $\begin{array}{l}\text { Xishuangbanna Dai Autonomous } \\
\text { Prefecture }\end{array}$ & Yunnan Province & $1953-1-24$ & Jinghong City \\
\hline $\mathrm{DMU}_{21}$ & $\begin{array}{l}\text { Dai-Jingpo Autonomous Prefecture of } \\
\text { Dehong }\end{array}$ & Yunnan Province & $1953-7-24$ & Luxi Town \\
\hline $\mathrm{DMU}_{22}$ & Lisu Autonomous Prefecture of Nujiang & Yunnan Province & $1954-8-23$ & Lushui Town \\
\hline $\mathrm{DMU}_{23}$ & Bai Autonomous Prefecture of Dali & Yunnan Province & $1956-11-22$ & Dali City \\
\hline $\mathrm{DMU}_{24}$ & Tibetan Autonomous Prefecture of Diqin & Yunnan Province & $1957-9-13$ & $\begin{array}{l}\text { Zhongdian } \\
\text { County }\end{array}$ \\
\hline $\mathrm{DMU}_{25}$ & $\begin{array}{l}\text { Honghe Hani and Yi Autonomous } \\
\text { Prefecture }\end{array}$ & Yunnan Province & $1957-11-18$ & Mengzi County \\
\hline $\mathrm{DMU}_{26}$ & $\begin{array}{l}\text { Wenshan Zhuang and Miao Autonomous } \\
\text { Prefecture }\end{array}$ & Yunnan Province & $1958-4-1$ & Wenshan County \\
\hline $\mathrm{DMU}_{27}$ & Yi Autonomous Prefecture of Chuxiong & Yunnan Province & $1958-4-15$ & Chuxiong City \\
\hline $\mathrm{DMU}_{28}$ & Tibetan Autonomous Prefecture of Ganze & Sichuan Province & $1950-11-24$ & Kangding County \\
\hline $\mathrm{DMU}_{29}$ & $\begin{array}{l}\text { Aba Tibetan and Qiang Autonomous } \\
\text { Prefecture }\end{array}$ & Sichuan Province & $1953-1-1$ & Barkam County \\
\hline $\mathrm{DMU}_{30}$ & Yi Autonomous Prefecture of Liangshan & Sichuan Province & $1952-10-1$ & Xichang City \\
\hline
\end{tabular}

Decision of the Central Committee on Some Major Issues Concerning Comprehensively Deepening the Reform was adopted at the Third Plenary Session of the 18th Central Committee of the Communist Party of China in which "improving the general transfer payment growth mechanism, focusing on increasing the growth of the transfer payment to minority areas and poor areas, accelerating the improvement of modern market system" have been presented. China's natural resource bases are uneven in minority areas, the development degrees are different, economic and social development of ethnic minority regions are out of balance. This paper applies DEA model for quantitative comparison and analysis the resource allocation in ethnic autonomous prefectures in China in order to optimize the resources allocation, set some efficiency of differentiated support policy recommendations for the relevant government departments.

\section{An analysis model of resource allocation efficiency in ethnic minority autonomous prefecture}

Under specific product conditions, groups of various production factors inputs possible producing maximum output is the core of the economic production theory. The production possibility boundary which is described by production function in the production theory model is generally called production frontier. The gap between actual production status and production boundary reflects the efficiency level of the production, that is, the technical efficiency, which also is known as resource allocation efficiency, describes a degree of resource allocation for production factors. The study on measure of resource allocation efficiency began in 1957 by economist Farrell 
Michaell, who oriented to production frontier ideas, developed and proposed the parametric method and non parametric method for research of the production frontier. Parameter method needs to construct a specific production function, which estimates the function parameters in production frontier, completes constructing the frontier function parameters; The non parametric method does not require prior assumptions and estimate parameters to structure the concrete function form, but observe a large number of actual data according to a certain production efficiency standard to find the relative effective point in production frontier.Non parametric effect of production frontier theory-Data Envelopment Analysis (abbreviated as DEA) is put forward by U.S economist A.Charnes et al to appraise relative validity of decision making unit in 1978, which also is an econometrics method.

\section{1 $C^{2} R$ Model and Comprehensive Efficiency Measure of Data Envelopment Analysis}

Use DEA to determine the comprehensive efficiency of resources allocation, the general use of $\mathrm{C}^{2} \mathrm{R}$ model was determined and described as follows:

There are n decision making units (DMU), each of which has a m DMU type of "input X", as well as S type of "output Y". Record the input variable of the first $j$ DMU as $X_{j}=\left(x_{1 j}, x_{2 j}, \ldots, x_{m j}\right)^{T}, j=1,2, \ldots n$; the output variable of first $j$ DMU is recorded as $Y_{j}=\left(y_{1 j}, y_{2 j} \ldots . y_{n j}\right)^{T}, j=1,2, \ldots n$.Using $\left(X_{j}, Y_{j}\right)$ represents the first $j$ decision making unit $\mathrm{DMU}_{\mathrm{j}}$, and its data structure is shown in table 2 .

Table 2. N Decision Making Unit DMU Input and Output Data Structure.

\begin{tabular}{|c|c|c|c|c|c|c|c|c|c|}
\hline $\mathrm{v}$ & $\mathrm{DMU}_{1}$ & $\mathrm{DMU}_{2}$ & $\ldots$ & $\mathrm{DMU}_{\mathrm{n}}$ & $\mathrm{u}$ & $\mathrm{DMU}_{1}$ & $\mathrm{DMU}_{2}$ & $\ldots$ & DMUn \\
\hline $\mathrm{v}_{1}$ & $\mathrm{x}_{11}$ & $\mathrm{x}_{12}$ & $\ldots$ & $\mathrm{x}_{1 \mathrm{n}}$ & $\mathrm{u}_{1}$ & $\mathrm{y}_{11}$ & $\mathrm{y}_{12}$ & $\ldots$ & $\mathrm{y}_{1 \mathrm{n}}$ \\
\hline $\mathrm{v}_{2}$ & $\mathrm{x}_{21}$ & $\mathrm{x}_{22}$ & $\ldots$ & $\mathrm{x}_{2 \mathrm{n}}$ & $\mathrm{u}_{2}$ & $\mathrm{y}_{21}$ & $\mathrm{y}_{22}$ & $\ldots$ & $\mathrm{y}_{2 \mathrm{n}}$ \\
\hline$\ldots$ & $\ldots$ & $\ldots$ & $\ldots$ & $\ldots$ & $\ldots$ & $\ldots$ & $\ldots$ & $\ldots$ & $\ldots$ \\
\hline $\mathrm{v}_{\mathrm{m}}$ & $\mathrm{x}_{\mathrm{m} 1}$ & $\mathrm{x}_{\mathrm{m} 2}$ & $\ldots$ & $\mathrm{x}_{\mathrm{mn}}$ & $\mathrm{u}_{\mathrm{s}}$ & $\mathrm{Y}_{\mathrm{s} 1}$ & $\mathrm{Y}_{\mathrm{s} 2}$ & $\ldots$ & $\mathrm{Y}_{\mathrm{sn}}$ \\
\hline
\end{tabular}

Setting $v=\left(v_{1}, v_{2} \ldots v_{n}\right)^{T}$ represents $m$ input indicator corresponding to the weight coeffective vector, Setting $\mathrm{u}=\left(\mathrm{u}_{1}, \mathrm{u}_{2} \ldots \mathrm{u}_{\mathrm{s}}\right)^{\mathrm{T}}$ represents s output indicator corresponding to the weight coeffective vector, so each decision making unit $\mathrm{DMU}_{\mathrm{j}}$ has corresponding efficiency evaluation index:

$$
h_{j}=\frac{u^{T} Y_{j}}{v^{T} X_{j}} \quad j=1,2, \ldots ., n
$$

Proper choice of the weight coeffective of $v$ and $u$, makes them meet $h_{j} \leq 1, j=1,2, \ldots, n$. Evaluate the efficiency of $\mathrm{j}_{0}$ decision making unit $\mathrm{DMU}_{\mathrm{j} 0}\left(\mathrm{X}_{0}, \mathrm{Y}_{0}\right)$. For any $\mathrm{DMU}_{\mathrm{j}}$, the production possibility set is :

Construct the following maximization $\operatorname{model}(\overline{\mathrm{p}}))$ :

$$
\mathrm{T}=\left\{(\mathrm{X}, \mathrm{Y}) \mid \sum_{\mathrm{j}=1}^{\mathrm{n}} \mathrm{X}_{\mathrm{j}} \lambda_{\mathrm{j}} \leq \mathrm{X}, \sum_{\mathrm{j}=1}^{\mathrm{n}} \mathrm{Y}_{\mathrm{j}} \lambda_{j} \geqq \mathrm{Y}, \lambda_{\mathrm{j}} \geqq 0, \mathrm{j}=1,2, \ldots, \mathrm{n}\right\}
$$

$$
\text { (p) }\left\{\begin{array}{c}
\operatorname{maxh}_{\mathrm{o}}=\frac{\mathrm{u}^{\mathrm{T}} \mathrm{Y}_{0}}{\mathrm{v}^{\mathrm{T}} \mathrm{x}_{0}}=\mathrm{V}_{\mathrm{p}} \\
\mathrm{s} . \mathrm{t} . \\
\mathrm{h}_{\mathrm{j}}=\frac{\mathrm{u}^{\mathrm{T} Y_{\mathrm{j}}}}{\mathrm{v}^{\mathrm{T}} \mathrm{x}_{\mathrm{j}}} \leq 1, \mathrm{j}=1,2 \ldots, \mathrm{n} \\
\underline{\mathrm{v}} \geqq 0, \mathrm{u} \geqq 0
\end{array}\right.
$$

let $\mathrm{t}=1 /\left(\mathrm{v}^{\mathrm{T}} \mathrm{X}_{0}\right), \mathrm{w}=\mathrm{tv}, \mu=\mathrm{tu}$, using Charnes-Cooper transformation, $\overline{\mathrm{p}}$ can be described as an equivalent linear programming problem $\left(\mathrm{P}_{1}\right)$ (that is, $\mathrm{C}^{2} \mathrm{R}$ model):

Given the following $\mathrm{C}^{2} \mathrm{R}$ model DEA effective definition:

$$
\left(P_{1}\right)\left\{\begin{array}{c}
\max \mu^{T} Y_{0}=V_{p 1} \\
\text { s.t. } \\
w^{\tau} x_{j}-u^{\tau} Y_{j} \geqq 0, j=1,2, \ldots, n \\
w^{\tau} x_{0}=1 \\
w \geqq 0, \mu \geqq 0
\end{array}\right.
$$

If Optimal solution of linear programming problem $\left(\mathrm{P}_{1}\right) \mathrm{w}_{0}$ and $\mathrm{u}_{0}$ meet $\mathrm{V}_{\mathrm{pl}}=\mathrm{u}_{0}{ }^{\mathrm{T}} \mathrm{Y}_{0}=1$, the $\mathrm{DMU}$ i0 is called weak DEA efficiency; if the linear planning problems $\left(\mathrm{P}_{1}\right)$ has an optimal solution of $\mathrm{w}_{0}$ and $\mathrm{u}_{0}$ meet the $\mathrm{V}_{\mathrm{pl}}=$ $\mathrm{u}_{0}{ }^{\mathrm{T}} \mathrm{Y}_{0}=1, \mathrm{w}_{0}>0, \mathrm{u}_{0}>0, \mathrm{DMU}_{\mathrm{j} 0}$ is called DEA efficiency

The Non Aqi Mead infinitesimal $\varepsilon$ is introduced into $C^{2} \mathrm{R}$ model which is described as $\left(\mathrm{P}_{1 \varepsilon}\right)$ :

$$
\left(P_{1 \varepsilon}\right)\left\{\begin{array}{c}
\max \mu^{T} Y_{0}=V_{p 1 \varepsilon} \\
s . t \\
w^{\tau} X_{j}-\mu^{\tau} Y_{j} \geqq 0, j=1,2, \ldots, n, \\
w^{\tau} X_{0}=1 \\
w^{t} \geqq \varepsilon e^{-T}, \mu{ }^{T} \geqq \varepsilon e^{+T}
\end{array}\right.
$$


where, $\mathrm{e}^{-\mathrm{T}}=(1,1, \ldots, 1) \in \mathrm{E}_{\mathrm{m}}, \mathrm{e}^{+\mathrm{T}}=(1,1, \ldots, 1) \in \mathrm{E}_{\mathrm{s}}, \varepsilon$ is Non Aqi Mead infinitesimal.

Introducing variable $\mathrm{s}^{-}$And $\mathrm{s}^{+}$, pairing $\mathrm{C}^{2} \mathrm{R}$ model $\left(\mathrm{D}_{1 \varepsilon}\right)$ is:

$$
\left(D_{1 \varepsilon}\right)=\left\{\begin{array}{c}
\min \left[\theta-\varepsilon\left(e^{-T} s^{-}+e^{+T} s^{+}\right)\right]=V_{D 1 \varepsilon} \\
s . t \\
\sum_{j=1}^{n} X_{j} \lambda_{j}-s^{-}=\theta X_{0} \\
\sum_{j=1}^{n} X_{j} \lambda_{j}-s^{+}=X_{0} \\
\lambda_{j^{\prime}}, j=1,2, \ldots, n \\
s^{-} \geqq 0, s^{+} \geqq 0
\end{array}\right.
$$

Suppose the optimal solution of $C^{2} \mathrm{R}$ model $\left(\mathrm{D}_{1 \varepsilon}\right)$ are $\lambda^{*}, \mathrm{~s}^{-{ }^{*}}, \mathrm{~s}^{+*} \cdot \theta^{*}$, when $\theta^{*}=1$, and $\mathrm{s}^{-*}=0, \mathrm{~s}^{+*}=1$, the $\mathrm{DMU} \mathrm{J}_{\mathrm{J}}$ ${ }_{0}$ is DEA effective; when $\theta^{*}<1$ or $\mathrm{s}^{-*}=0, \mathrm{~s}^{+*} \neq 1$, the $\mathrm{DMU}_{\mathrm{j} 0}$ is non DEA efficiency. According to $\mathbf{C}^{2} \mathbf{R}$ model operation results $\theta(0 \leq \theta \leq 1)$ is comprehensive efficiency of decision making unit.

\subsection{Data Envelopment Analysis BC2 Model and Scale Efficiency and Technical Efficiency Measurement}

The scale efficiency and technical efficiency of resource allocation were determined by DEA, and the BC ${ }^{2}$ model was used.

There is a hypothesis in prior $C^{2} R$ model $\left(D_{1 \varepsilon}\right): C^{2} R$ model $\left(D_{1 \varepsilon}\right)$ is scale invariant, the hypothesis is very strict, and difficult to meet this condition in practice. So, adding a convexity assumptions in the $C^{2} R$ model $\left(D_{1 \varepsilon}\right): \sum_{j=1}^{n} \lambda_{j}=1$, then production possibility set becomes as follows:

$\mathrm{T}_{\mathrm{BC}^{2}}=\left\{(\mathrm{X}, \mathrm{Y}) \mid \sum_{\mathrm{j}=1}^{\mathrm{n}} \mathrm{X}_{\mathrm{j}} \lambda_{\mathrm{j}} \leq \mathrm{X}, \sum_{\mathrm{j}=1}^{\mathrm{n}} \mathrm{Y}_{\mathrm{j}} \lambda_{\mathrm{j}} \geqq \mathrm{Y}, \sum_{\mathrm{j}=1}^{\mathrm{n}} \lambda_{\mathrm{j}}=1, \lambda_{\mathrm{j}} \geqq 0, \mathrm{j}=1,2, \ldots, \mathrm{n}\right\}$

After removing cone condition in $\mathrm{C}^{2} \mathrm{R}$ model, make DEA efficiency evaluation which is the input of the DEA model - the $\mathrm{BC}^{2}$ model $\left(\mathrm{P}_{2}\right)$, bases on the production possibility set $\mathrm{T}_{\mathrm{BC}}{ }^{2}$ :

And dual problem DEA model -- $\mathrm{BC}^{2}$ model $\left(\mathrm{D}_{2}\right)$

$$
\left(P_{2}\right)\left\{\begin{array}{c}
\max \left(\mu^{t} Y_{0}+u_{0}\right)=V_{P_{2}} \\
\text { s.t. } \\
w^{T} X_{j}-\mu^{T} Y_{j}-u_{0} \geqq 0, j=1,2, \ldots n \\
w^{T} x_{0}=1 \\
w \geqq 0, \mu \geqq 0
\end{array}\right.
$$

$$
\left(D_{2}\right)\left\{\begin{array}{c}
\min \theta=V_{D_{2}} \\
s . t . \\
\sum_{j=1}^{n} X_{j} \lambda_{j} \leq \theta X_{0} \\
\sum_{j=1}^{n} Y_{j} \lambda_{j} \geqq Y_{0} \\
\sum_{j=1}^{n} \lambda_{j}=1 \\
\lambda_{j} \geqq 0, j=1,2, \ldots, n
\end{array}\right.
$$

Introduce Non Aqi Mead infinitesimal $\varepsilon$ in DEA model $-\mathrm{BC}^{2}$ model,get $\mathrm{BC}^{2} \operatorname{model}\left(\mathrm{P}_{2 \varepsilon}\right)$ :

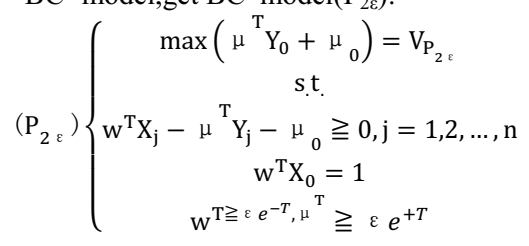

Where $, \mathrm{e}^{-\mathrm{T}}=(1,1, \ldots, 1) \in \mathrm{E}_{\mathrm{m}}, \mathrm{e}^{+\mathrm{T}}=(1,1, \ldots, 1) \in \mathrm{E}_{\mathrm{s}}, \varepsilon$ is the Non Aqi Mead infinitesimal. when introduction of variable $\mathrm{s}^{-}$and $\mathrm{s}^{+}$, dual $\mathrm{BC}^{2}$ model $\left(\mathrm{D}_{2 \varepsilon}\right)$ is :

In which, $\mathrm{e}^{-\mathrm{T}}=(1,1, \ldots, 1) \in \mathrm{E}_{\mathrm{m}}, \mathrm{e}^{+\mathrm{T}}=(1,1, \ldots, 1) \in \mathrm{E}_{\mathrm{s}}, \varepsilon$ is the Non Aqi Mead infinitesimal.

$$
\left(D_{2 \varepsilon}\right)\left\{\begin{array}{c}
\min \left[\theta-\varepsilon\left(e^{-T} s^{-}+e^{+T} s^{+}\right)\right]=V_{D_{2 \varepsilon}} \\
s . t . \\
\sum_{j=1}^{n} \lambda_{j} X_{j}+s^{-}=\theta X_{0} \\
\sum_{j=1}^{n} \lambda_{j} Y_{j}-s^{+}=Y_{0} \\
\sum_{j=1}^{n} \lambda_{j}=1, \lambda_{j} \geqq 0, j=1,2, \ldots, n \\
s^{-} \geqq 0, s^{+} \geqq 0
\end{array}\right.
$$

Suppose the optimal solution of $C^{2} \mathrm{R}$ model $\left(\mathrm{D}_{2 \varepsilon}\right)$ are $\lambda^{*}, \mathrm{~s}^{-{ }^{*}}, \mathrm{~s}^{+*} \theta^{*}$, when $\theta^{*}=1$, and $\mathrm{s}^{-*}=0, \mathrm{~s}^{+*}=1$, the DMU $\mathrm{J} 0$ is DEA effective; when $\theta^{*}<1$ or $\mathrm{s}^{-*}=0, \mathrm{~s}^{+*} \neq 1$, the $\mathrm{DMU}_{\mathrm{j} 0}$ for non DEA effective. 
In short, the previous $\mathbf{C}^{2} \mathbf{R}$ model represents the comprehensive effect of the evaluated object, while the $\mathrm{BC}^{2}$ model represents the technical efficiency of the evaluated object, that is, the $B C^{2}$ model operating results $\theta(0 \leq \theta \leq 1)$ is to be evaluated technical efficiency.

\section{Evaluation indicators system of resource allocation efficiency in ethnic minority autonomous prefecture}

Efficiency refers to the relationship between input and output or cost and benefit, and its essence is the general name of effective resources allocation, input versa output capability. the efficiency of evaluation object, according to different purposes of study, can be divided into technical efficiency, scale efficiency and comprehensive efficiency. Among them, the technical efficiency reflects the ability of the maximum output, while the scale efficiency reflects the suitability of the investment scale. Using $\mathbf{C}^{2} \mathbf{R}$ model to determine the comprehensive efficiency and utilization $\mathbf{B C}^{2}$ models to determine the technical efficiency, can get scale efficiency $=$ comprehensive efficiency/technical efficiency, and then comprehensive measure evaluated object scale efficiency, technical efficiency and overall efficiency as well as efficiency comparison in similar evaluated object.

\subsection{Input Indicator}

Resource allocation efficiency of the input indicators mainly include three aspects of human, financial and material resources, capital investment and human capital which constitute the basic elements of economic development, especially the contradiction between economic development and demand for talent becomes an important factor restricting in minority areas. Generally selecting the number of people with a certain degree of education as a measure of indicator, this paper replaces permanent resident population as this indicator. China has increased the financial support to the minority regions, such as high speed growth of fixed assets investment and the scale of fiscal expenditure. Therefore, selection of permanent resident population, financial expenditure, fixed assets investment as Input Indicators to measure the efficiency of resources allocation.

\subsection{Output Indicator}

Local fiscal revenue is an indicator of regional comprehensive strength, which shows the financial resources of local government as well as a very important role in measuring the efficiency of resource allocation in a region. Average capita fiscal revenue is an important indicator to measure economic development and economic strength for a country or a region. GDP reflect the new creation value, and it is the final outcome of the national economic activities. Urban disposable income and rural per capita net income indicate free disposable income of urban residents and the development of rural economy, respectively. Therefore, in this paper, selection of local fiscal revenue, GDP, per capita income, urban disposable income, rural per capita net income as output indicators for measure of resource allocation efficiency. The concrete index system is shown in Table 3

Table 3. Evaluation Index System of Resource Allocation Efficiency in Minority Autonomous Prefecture.

\begin{tabular}{|c|c|}
\hline \multirow{4}{*}{ Input } & Secondary Index \\
\hline \multirow{4}{*}{ Primary Index } & Permanent Resident Population \\
\cline { 2 - 2 } & Plant Asset Investment \\
\cline { 2 - 2 } & Per Capita Fiscal Expenditure \\
\hline \multirow{4}{*}{ Output } & Local Fiscal Revenue \\
\cline { 2 - 2 } & GDP \\
\cline { 2 - 2 } & Per Capita FiscalRevenue \\
\cline { 2 - 2 } & Urban Disposable Income \\
\cline { 2 - 2 } & Rural Per Capita Net Income \\
\hline
\end{tabular}

\section{Determination of resource allocation efficiency based on the c2r model and bc2 model inminority autonomous prefecture}

Import input indicators and output indicators data for 30 Minority Autonomous Prefecture into DEAP2.1 software, resource allocation efficiency results based on $\mathbf{C}^{2} \mathbf{R}$ and $\mathbf{B C}^{2}$ model are showed in table 4 .

Table 4 shows that the technical efficiency of the 30 minority autonomous prefecture is 0.918 , the average technical efficiency is 0.949 . From its resource allocation efficiency score, it's known that a total of 18 ethnic 
autonomous prefectures are DEA effective, which represent resource allocation efficiency optimized when input fixed.

Among them there are 12 Minority Autonomous Prefecture of resource allocation with non DEA effective, DMU14, DMU15 pure technical efficiency value is 1.000 , which indicate that the 2 Mnority Autonomous Prefecture with non DEA effective because of low scale efficiency, requiring reasonable control scale of investment to improve the efficiency of resource allocation; the comprehensive technical efficiency and pure technical efficiency of $\mathrm{DMU}_{2}, \mathrm{DMU}_{3}, \mathrm{DMU}_{4}, \mathrm{DMU}_{5}, \mathrm{DMU}_{16}, \mathrm{DMU}_{17}, \mathrm{DMU}_{19}, \mathrm{DMU}_{21}, \mathrm{DMU}_{28}, \mathrm{DMU}_{29}$ do not equal to 1 . 000 , indicating that the non DEA effective results from not only inappropriate scale of inputs but also lower output level. According to the 10 Minority Autonomous Prefecture, the improvement measurements are put forward by introducing slack variables into DEA model. Analysis for Resource allocation efficiency in 30 Minority Autonomous Prefecture, non DEA effective accounts for $40 \%$, which shows that there is a great potentiality in resource allocation in the Minority Autonomous Prefecture.

Table 4. Efficiency of Input-Output in China's Minority Autonomous Prefectures.

\begin{tabular}{|c|c|c|c|c|c|}
\hline $\begin{array}{c}\text { Decision } \\
\text { Making Module }\end{array}$ & Technical Effective & $\begin{array}{c}\text { Pure Technical } \\
\text { Efficiency }\end{array}$ & Scale Efficiency & Appraisal Result & Scale Efficiency State \\
\hline $\mathrm{DMU}_{t}$ & 1.000 & 1.000 & 1.000 & DEA Effective & Invariable \\
\hline $\mathrm{DMU}_{2}$ & 0.593 & 0.678 & 0.874 & NonDEA Effective & Decreasing \\
\hline $\mathrm{DMU}_{3}$ & 0.603 & 0.620 & 0.974 & Non DEA Effective & Decreasing \\
\hline $\mathrm{DMU}_{4}$ & 0.663 & 0.881 & 0.752 & Non DEA Effective & Decreasing \\
\hline $\mathrm{DMU}_{5}$ & 0.779 & 0.817 & 0.954 & Non DEA Effective & Decreasing \\
\hline $\mathrm{DMU}_{6}$ & 1.000 & 1.000 & 1.000 & DEA Effective & Invariable \\
\hline $\mathrm{DMU}_{7}$ & 1.000 & 1.000 & 1.000 & DEA Effective & Invariable \\
\hline $\mathrm{DMU}_{8}$ & 1.000 & 1.000 & 1.000 & DEA Effective & Invariable \\
\hline $\mathrm{DMU}_{9}$ & 1.000 & 1.000 & 1.000 & DEA Effective & Invariable \\
\hline $\mathrm{DMU}_{10}$ & 1.000 & 1.000 & 1.000 & DEA Effective & Invariable \\
\hline $\mathrm{DMU}_{11}$ & 1.000 & 1.000 & 1.000 & DEA Effective & Invariable \\
\hline $\mathrm{DMU}_{12}$ & 1.000 & 1.000 & 1.000 & DEA Effective & Invariable \\
\hline $\mathrm{DMU}_{13}$ & 1.000 & 1.000 & 1.000 & DEA Effective & Invariable \\
\hline $\mathrm{DMU}_{14}$ & 0.943 & 1.000 & 0.943 & Non DEA Effective & Decreasing \\
\hline $\mathrm{DMU}_{15}$ & 0.988 & 1.000 & 0.988 & Non DEA Effective & Increasing \\
\hline $\mathrm{DMU}_{16}$ & 0.778 & 0.780 & 0.997 & Non DEA Effective & Increasing \\
\hline $\mathrm{DMU}_{17}$ & 0.813 & 0.900 & 0.904 & Non DEA Effective & Decreasing \\
\hline $\mathrm{DMU}_{18}$ & 1.000 & 1.000 & 1.000 & DEA Effective & Invariable \\
\hline $\mathrm{DMU}_{19}$ & 0.899 & 0.942 & 0.955 & Non DEA Effective & Decreasing \\
\hline $\mathrm{DMU}_{20}$ & 1.000 & 1.000 & 1.000 & DEA Effective & Invariable \\
\hline $\mathrm{DMU}_{21}$ & 0.973 & 0.978 & 0.995 & Non DEA Effective & Increasing \\
\hline $\mathrm{DMU}_{22}$ & 1.000 & 1.000 & 1.000 & DEA Effective & Invariable \\
\hline $\mathrm{DMU}_{23}$ & 1.000 & 1.000 & 1.000 & DEA Effective & Invariable \\
\hline $\mathrm{DMU}_{24}$ & 1.000 & 1.000 & 1.000 & DEA Effective & Invariable \\
\hline $\mathrm{DMU}_{25}$ & 1.000 & 1.000 & 1.000 & DEA Effective & Invariable \\
\hline $\mathrm{DMU}_{26}$ & 1.000 & 1.000 & 1.000 & DEA Effective & Invariable \\
\hline $\mathrm{DMU}_{27}$ & 1.000 & 1.000 & 1.000 & DEA Effective & Invariable \\
\hline $\mathrm{DMU}_{28}$ & 0.623 & 0.902 & 0.691 & Non DEA Effective & Decreasing \\
\hline $\mathrm{DMU}_{29}$ & 0.818 & 0.979 & 0.836 & Non DEA Effective & Decreasing \\
\hline $\mathrm{DMU}_{30}$ & 1.000 & 1.000 & 1.000 & DEA Effective & Invariable \\
\hline
\end{tabular}




\begin{tabular}{|l|l|l|l|l|l|}
\hline Average Value & 0.918 & 0.949 & 0.964 & & \\
\hline
\end{tabular}

In 30 Minority Autonomous Prefecture, 18 of which are scale efficiency invariable, 9 of which keep decreasing state, 3 of which keep increasing state, and the proportion are $60 \%, 30 \%$ and $10 \%$ respectively.

Those show that the scale efficiency of the 30 minority autonomous prefecture keep the same or increasing state. The reason is that in recent years, China government increase input in Minority Autonomous Prefecture. For the Minority Autonomous Prefecture of decreasing scale efficiency, it should be appropriately controlled to increase output efficiency. For the Minority Autonomous Prefecture with increasing scale efficiency, it should be appropriate to expand the scale of investment in order to improve the efficiency of input-output.

\section{Policy suggestion}

From the above analysis, this paper proposes some suggestions to optimize Minority Autonomous Prefecture resource allocation efficiency.

\subsection{Adhere to the Principles of Classified Guidance}

The reasons for non DEA effective in Ethnic Minority Autonomous Prefecture resource allocation are different, therefore, we should first find out the factors ineffective of resource allocation, then optimize resources allocation measures in the Minority Autonomous Prefecture to improve the efficiency of resource allocation. In view of the low efficiency of resource allocation, the investment scale of fixed assets should be controlled, guide direction of investment, optimize the structure of fiscal expenditure and establish the regional economic and social development to match the personnel training plan, strengthen the construction of talent team according to the actual need; for resource allocation problems resulting from pure technical efficiency, not only need reasonable adjustments of fixed assets, fiscal expenditure scale and structure, but also pay attention to strengthen the building of local resources, maintain a certain economic growth rate, improve urban disposable income and rural per capita income to improve the efficiency of resource allocation.

\subsection{Implement of Differentiated National Support Policies}

China's natural resource bases in ethnic minority regions are with traits of uneven, different levels of economic and social development, weak self accumulation capacity, especially require funding support. But the "GSP" financial support without considering the actual needs of local, the pertinence is not strong. Therefore, it should differentiate national funds support policy, establish national regions transfer payment mechanism according to the input redundancy and output shortfall analysis results; determine funding support level according to actual demands. All those can effectively improve the efficiency of resource allocation in minority regions.

\subsection{Multiple Supports for Economic and Social Development in Minority Areas}

The factors that affect the efficiency of resource allocation in ethnic areas from many aspects, such as insufficient investment scale, irrational industrial structure, uneven educational level and the difficulty of talent introduction, which affect their economic and social development. Resource allocation in minority areas needs national policy support, financial support, education and personnel support, but in every minority area of specific performance is not identical from only unilateral financial support to a full range of support. Therefore, when the state and the government take specific support steps for the minority regions, it is necessary to consider natural resource endowment, the degree of market development, economic and social development level, self accumulated ability factors. The implementation of multiple support programs, abandoning "foot painful medicine foot" and "headache medicine head".

\section{Acknowledgement}

This research was financially supported by the State Ethnic Affairs Commission Foundation (NO15064) and Hubei University for Nationalities Teaching Research Project (NO2015JY027).

\section{References}

1. Chen MK, “Two Forms of An Equity Index for Resource Allocation to Minority Groups,"A Journal Of Medical Care Organization, Provision And Financing ,1976,13 (3),pp.228-32

2. Chen N, et al, "Equity of Health Resources Allocation in Minority Regions of Sichuan Province,"Journal of Sichuan University. Medical Science Edition, 2016, 47 (2), pp.238-43 
3. Jiang Shuxia, et al, "An Evaluation of Efficiency and Productivity Change Based on DEA for Fujian Science and Technology Enterprises," Statistical Research, 2008, 25 (12), pp.30-35

4. Ye Rui, Yang Jianfei, Chang Gao, "The Measures and Decomposition for the Efficiency of China's Provincial High Technology Industry,’Quantitative Economic and Technical Economic Research, 2012 (7), pp.3-17

5. Hao Qian,“Minority Regional Industrial Structure Optimization Based on Financial Return Support ,'Guizhou National Studies, 2015, 36(172),pp.124-127

6. Pan Bao,"The Dilemma of Natural Resources in the Economic Development of China's Minority Nationalities , "Guizhou Ethnic Studies, 2014,35(156),pp.94-97

7. Liu Guiqing,"A Research on the Coordinated Development of Population, Resources, Environment and Economy in Ethnic Minority Areas, "Guizhou National Research, 2013,34 (151),pp.79-82

8. Lu QS,Gan SD, Zhang JZ, "Developing Comprehensive Abilities of Accounting Undergraduates through Curricular Reconstruction ," ICESD2015,Nanjing,Vol .1,pp278-282,December 2015

9. Zhang JZ, "EnterpriseInternal Control's Fuzzy Comprehensive Evaluation and Application,” CME 2014, Shanghai,Vol.2, pp1795-1803, May 2014.

10. Zhang YT, Wang T, Li, XD, "Statistical Analysis Model of Money Laundering Risk Based on Behavior Detection Technology, ” ITME2014,Hongkong,Vol.1,PP174-179,April 2014. 